\title{
O PIBID E A FORMAÇÃO INICIAL DE PROFESSORES DE PSICOLOGIA
}

\author{
Thalita Saramago de Souza ${ }^{1}$ \\ Claudia Emanuela Honorio Hahn² \\ Jaqueline Batista de Oliveira Costa ${ }^{3}$
}

Agência Financiadora: PIBIC-UFGD

\begin{abstract}
Resumo:
O Programa Institucional de Bolsa de Iniciação à Docência - PIBID integra um conjunto de ações da Capes para a melhoria da qualidade da educação básica no Brasil. Acredita-se que o professor de Psicologia tem papel fundamental na formação moral, ética e política das novas gerações. Assim, o PIBID, enquanto proposta de trabalho com a Psicologia para melhoria da qualidade da educação básica, apresenta-se como uma alternativa viável a formação docente pretendida, e a melhoria da qualidade do ensino. Nesse sentido, este estudo tem como objetivo geral conhecer o impacto do Programa Institucional de Bolsa de Iniciação à Docência - PIBID sobre a formação inicial dos licenciandos em Psicologia, bem como identificar em que medida as experiências com o PIBID influenciam no interesse pelo futuro exercício da docência. Especificamente, pretende discutir o PIBID enquanto política pública de formação de professores; identificar quais razões levam os alunos de Psicologia a optarem por participar do PIBID e quantos querem, de fato, atuar na docência; discutir o impacto do PIBID sobre a formação inicial dos futuros professores de Psicologia e comparar o relato de alunos dos anos iniciais do curso de Psicologia com o de alunos do último ano do curso, sobre sua experiência no PIBID. Trata-se de uma pesquisa qualitativa que lançará mão das seguintes estratégias de coleta de dados: Análise documental e Entrevista semiestruturada com 30 alunos do $5^{\circ}$ ao $10^{\circ}$ semestre matriculados no curso de Psicologia. A análise dos dados, obedecerá a proposta de análise do conteúdo proposta por Bardin (1977).
\end{abstract}

Palavras-chave: Licenciatura. PIBID. Psicologia.

\begin{abstract}
:
The Institutional Scholarship Initiative Program - PIBID integrates a set of Capes actions to improve the quality of basic education in Brazil. It is believed that the Psychology teacher plays a fundamental role in the moral, ethical and political formation of the new generations. Thus, PIBID, as a proposal to work with Psychology to improve the quality of basic education, is presented as a viable alternative to the intended teacher training and the improvement of the quality of teaching. In this sense, this study has as general objective to know the impact of the PIBID on the initial formation of the graduates in Psychology, as well as to identify to what extent the experiences with the PIBID influence in the interest for the future exercise of teaching. Specifically, it intends to discuss PIBID as a public policy for teacher training; to identify what reasons lead the students of Psychology to choose to participate in PIBID and how many, in fact, want to act in teaching; to discuss the impact of PIBID on the initial

\footnotetext{
${ }^{1}$ Psicóloga: Universidade Federal da Grande Dourados (UFGD). Psicóloga residente do Programa de Residência Multiprofissional em Saúde do Hospital Universitário da Universidade Federal da Grande Dourados (HU/UFGD). E-mail: thalita.atanasio@gmail.com.

${ }^{2}$ Psicóloga: Universidade Federal da Grande Dourados (UFGD). E-mail: emanuelahahn@ @otmail.com.

${ }^{3}$ Doutora em Educação: Pontifícia Universidade Católica de São Paulo (PUC). Professora Titular da Universidade Federal da Grande Dourados (UFGD). E-mail: jakbatista15@gmail.com.
} 
training of future Psychology teachers and to compare the students' reports from the initial years of the Psychology course with those of the last year students of the course about their experience in PIBID. It is a qualitative research that will use the following data collection strategies: Documentary analysis and semi-structured interview with 30 students from the 5th to 10th semester enrolled in the Psychology course. The analysis of the data will follow the proposal of analysis of the content proposed by Bardin (1977).

Keywords: Graduation. PIBID. Psychology.

\section{Introdução}

A situação da qualidade do ensino básico e público no Brasil revela uma realidade preocupante. Dados estatísticos têm demonstrado a urgente necessidade de uma análise criteriosa, seguida de alternativas que possam reverter a situação. Estudos têm demonstrado que a formação inicial e continuada do professor constitui elemento fundamental para melhoria da qualidade do ensino no Brasil (LIBÂNEO, 1990, 2004; LUCKESI, 1994; ZABALA, 1998).

O Programa Institucional de Bolsa de Iniciação à Docência - PIBID integra um conjunto de ações da Coordenação de Aperfeiçoamento de Pessoal de Nível Superior CAPES, para a melhoria da qualidade da educação básica no Brasil, colocado em prática por meio da Política Nacional de Formação de Profissionais do Magistério da Educação Básica (Decreto n. 6.755, de 20 de janeiro de 2009). O PIBID foi criado com a finalidade de melhorar a formação do professor e, consequentemente, melhorar a qualidade do ensino na escola básica. O Programa foi instituído por Portaria Normativa do Ministério de Educação MEC - de número 38, em 12 de dezembro de 2007, tendo como uma de suas finalidades: incentivar estudantes das licenciaturas das Instituições Federais de Educação Superior (IFES) e Centros Federais de Educação Tecnológica (CEFETs) a optarem pela docência e a se comprometerem com a própria formação profissional (BRASIL, 1996).

Nesse sentido, o PIBID surge como alternativa destinada a suprir a carência de professores nos diversos níveis de ensino no Brasil, especialmente no ensino médio. O inciso I do artigo $1^{\circ}$ encontra-se explicito esse propósito: “incentivar a formação de professores para a educação básica, especialmente para o ensino médio" (BRASIL, 1996). Além desse propósito, dois outros aspectos destacam-se: incentivar os professores formadores das licenciaturas a participarem mais ativamente da vida das escolas desse nível de ensino, conhecendo-as "por dentro", e aos professores da escola básica a se responsabilizarem pela formação dos futuros professores.

O PIBID é um programa de grande envergadura, uma vez que favorece maior aproximação entre as instituições formadoras e as escolas em que os estágios e as práticas dos 
licenciandos acontecem. Tal aproximação possibilita aos estudantes, futuros professores, a ampliação de espaço para o exercício da docência; a formação continuada, e em serviço, associada a inicial, numa troca frutífera; o apoio a projetos inovadores construídos em parceria das escolas com as instituições formadoras.

Conforme já explicito, o PIBID vem suprir uma lacuna já bastante conhecida no Brasil: a falta de professores nos diversos níveis de ensino. Em decorrência desse fato, o programa inicialmente priorizou determinadas licenciaturas estendendo-se, posteriormente, as demais. Atualmente o Programa Institucional de Bolsa de Iniciação à Docência desenvolvese em diversos curso de licenciaturas da Universidade Federal da Grande Dourados - UFGD, dentre os quais se destaca o de Psicologia.

\section{O PIBID e Formação do Professor de Psicologia}

A licenciatura, ou formação de professores, sempre foi uma opção ofertada aos alunos de psicologia. Segundo Cirino et al (2007, p. 24) "a Licenciatura é uma habilitação possível nos cursos de Psicologia desde a implantação da lei no 4.119, de 27 de agosto de 1962, que os regulamenta no Brasil. Essa lei disserta em seu Art.1 ${ }^{\circ}$ que 'a formação em Psicologia far-se-á [...] em cursos de Bacharelado, Licenciatura e Psicologia"”.

O curso de Psicologia, nos últimos anos, ganhou novos contornos. A Resolução de número 05, de 15 de março de 2011 (BRASIL, 2011), que institui as Diretrizes Curriculares Nacionais para os cursos de graduação em Psicologia, a serem observadas pelas Instituições de Ensino Superior do País, estabelece em seu Art. 13 que a Formação de Professores de Psicologia ocorra "em um projeto pedagógico complementar e diferenciado, elaborado em conformidade com a legislação que regulamenta a formação de professores no País". Desse modo, esse projeto pedagógico deve ter como objetivos: a) complementar a formação dos psicólogos, articulando os saberes específicos da área com os conhecimentos didáticos e metodológicos, para atuar na construção de políticas públicas de educação, na educação básica, no nível médio, no curso Normal, em cursos profissionalizantes e em cursos técnicos, na educação continuada, assim como em contextos de educação informal como abrigos, centros socioeducativos, instituições comunitárias e outros; b) possibilitar a formação de professores de Psicologia comprometidos com as transformações político-sociais, adequando sua prática pedagógica às exigências de uma educação inclusiva; c) formar professores de Psicologia comprometidos com os valores da solidariedade e da cidadania, capazes de refletir, expressar e construir, de modo crítico e criativo, novos contextos de pensamentos e ação. 
A proposta complementar para a Formação de Professores de Psicologia estabelece, ainda, que as Instituições de Ensino Superior assegurem que o curso articule conhecimentos, habilidades e competências em torno dos seguintes eixos estruturantes: a) Psicologia, Políticas Públicas e Educacionais; b) Psicologia e Instituições Educacionais; c) Filosofia, Psicologia e Educação; d) Disciplinaridade e interdisciplinaridade (BRASIL, 2011). É nessa perspectiva formativa que a proposição do PIBID, enquanto alternativa de formação inicial de professores e estimulo a docência, se circunscreve, pois, acredita-se que o contato dos licenciandos de Psicologia com a realidade escolar pode agregar de maneira significativa: conhecimentos e experiências na e sobre a prática da docência, pode despertar nestes sujeitos a identificação e o gosto pelo exercício da profissão.

Acredita-se que o professor de Psicologia, tem papel fundamental na formação moral, ética e política das novas gerações. Contudo, compete as diferentes instâncias, nas quais a formação deste docente acontece, criar e gerenciar estratégias/alternativas que garantem uma formação capaz de dar a esse agente social autonomia para exercer sua função profissional e política, de modo a colaborar com a formação dos cidadãos.

Desse modo, acredita-se que o PIBID, enquanto proposta colaborativa de trabalho com a Psicologia para melhoria da qualidade da educação básica, apresenta-se e justifica-se como uma alternativa viável a formação docente pretendida. Nesse sentido, a presente proposta de pesquisa tem como objetivo geral conhecer o impacto do Programa Institucional de Bolsa de Iniciação à Docência - PIBID sobre a formação inicial dos licenciandos em Psicologia, bem como identificar em que medida as experiências com o PIBID influenciam no interesse pelo futuro exercício da docência. Especificamente pretende-se apresentar e discutir o PIBID enquanto política pública de formação de Professores; identificar as razões pelas quais os alunos de Psicologia optam por participar do PIBID e quantos querem, de fato, atuar na docência; comparar o relato de alunos dos anos iniciais do curso de Psicologia com o de alunos do último ano do curso sobre sua experiência no PIBID.

\section{Metodologia}

A Presente pesquisa foi desenvolvida por meio da aplicação de um questionário estruturado, junto aos alunos do curso de Psicologia da Universidade Federal da Grande Dourados - UFGD, tendo em vista identificar as razões que os levaram a participar do Programa de Bolsas de Iniciação à Docência e verificar se estes, de fato, pretendem atuar na docência depois de formados. 
São, atualmente, vinte e cinco alunos da licenciatura em Psicologia que participam do PIBID, porém, apenas dezoito acadêmicos matriculados do $6^{\circ}$ semestre ao $10^{\circ}$ semestre do curso, responderam ao questionário. O questionário foi estruturado de modo que, nas primeiras questões, os estudantes fornecessem informações de caráter pessoal, tendo em vistas traçar o perfil do grupo, e as últimas sete perguntas são abertas, sobre o envolvimento do licenciando com PIBID, as experiências enquanto bolsistas do Programa, e ainda, sobre o impacto que estas tiveram sobre sua formação.

Os dados coletados foram submetidos a procedimentos de análise qualitativa.

\section{Apresentação dos Resultados}

Dos acadêmicos que participaram dessa pesquisa, cinco acadêmicos estão cursando o $6^{\circ}$ semestre; onze estão cursando o $8^{\circ}$ semestre do curso; e dois, cursando o $10^{\circ}$ semestre do curso. Com relação ao ano de ingresso no Programa, dez relataram ter ingressado no ano de 2015, cinco ingressaram em de 2016 e três acadêmicos ingressaram no PIBID no ano de 2014.

Dentre os acadêmicos, apenas um participante afirmou possuir outra graduação, sendo ela a de bacharel em Serviço Social. Do total de participantes, onze acadêmicos alegaram possuir experiência na docência, antes de ingressar no Programa, dos quais cinco obtiveram essa experiência no Estágio Supervisionado de Formação de Professores, obrigatório para quem opta pela licenciatura. Um participante obteve experiência em uma préescola e um em um curso de Língua Estrangeira; os demais não declararam.

Quando questionados sobre a motivação que os levaram a participar do processo seletivo do Programa, os participantes deveriam elencar, por prioridade, de um a quatro, os motivos sugeridos no questionário para o ingresso no PIBID, ou, apontar outros motivos. Dos dezoito alunos participantes, 13 (treze) apontaram a garantia de formação acadêmica mais ampla como o fator que mais influenciou; a bolsa oferecida pelo Programa foi o segundo fator mais importante, apontado por 09 (nove) participantes; a identificação com a docência foi eleita o terceiro fator mais importante, indicada por 07 (sete) alunos; e por fim, as horas complementares necessárias para que o licenciado possa se formar, foi indicada como fator menos importante por 09 (nove) acadêmicos.

Outra questão abordada pelo questionário foi com relação as aspirações dos acadêmicos em atuar na docência após a graduação. Dentre eles, 07 (sete) bolsistas responderam que apresentam, sim, desejo de seguir esta área, e, onze afirmaram haver uma relação de dependência com outros fatores, tais como: a disponibilidade de campo de atuação na docência; o fato da Psicologia não constar como disciplina na grade curricular da escola 
básica, etc. isso foi possível perceber nos seguintes trechos: "[...] pretendia ingressar no ensino público ou privado como professora de psicologia, porém a psicologia ainda não está inserida na grade curricular" (participante 07), "gostaria de atuar dependendo das condições de ensino" (Participante 03). Um participante, ainda, afirmou não ter decidido em qual área irá atuar após o termino da graduação. Dos participantes que disseram 'sim' para o interesse na atuação na docência, 05 (cinco) afirmaram que a docência é uma opção de atuação quando saírem da Universidade, tal resposta é vista no seguinte trecho "sempre me identifiquei com a área e durante o tempo que estou ativa no projeto só fortaleci essa vontade" (participante 14).

Quando questionados sobre as suas experiências no PIBID, todos os participantes da pesquisa consideraram que a experiência como bolsista no PIBID tem sido positiva; para grande parte dos bolsistas, a experiência na docência tem sido gratificante e enriquecedora, para eles trata-se de "[...] uma atividade empolgante e desafiadora" (participante 01) e tem sido "[...] absurdamente gratificante contribuir com o desenvolvimento de temas tão importantes" (participante 02). Para quinze participantes, o PIBID representa maior contribuição em sua formação acadêmica, bem como em sua formação enquanto indivíduo. Isto é evidenciado quando dizem que o projeto "proporciona um grande aprendizado, tanto como profissional, como pessoal" (participante 08), e que as experiências vivenciadas no Projeto "[...] quebraram alguns paradigmas pessoais" (participante 05), afirmam, também que no PIBID "[...] enfrentamos desafios positivos e negativos que agregam na nossa formação como docente” (participante 07) e que o Programa, ainda, “[...] dá experiência de campo" (participante 10).

Outra questão que é bastante presente nos questionários possui relação com a experiência dos acadêmicos enquanto pibidianos. O Programa despertou nos acadêmicos a preocupação com os alunos da escola básica e com as demandas que os mesmos apresentam; cinco bolsistas afirmam ter tido essa preocupação durante a sua participação no Projeto. Dentre os participantes, quatro alegam que a experiência no PIBID proporciona conhecimento da docência na prática, além de possibilitar a associação dos conhecimentos teóricos à prática docente. Neste sentido, os acadêmicos afirmam que "é um momento em que temos o contato com a prática em sala de aula” (participante 14); “[...] aprender sobre o ensino na teoria é muito bom, mas quando você está na prática é melhor ainda, pois somente quando você se depara com a realidade é que o faz pensar e se adaptar melhor" (participante 03). Por fim, um participante afirmou que a experiência no PIBID fez com que despertasse nele o interesse em seguir a carreira docente. 
No questionário havia, também, perguntas relacionadas às contribuições que o PIBID proporcionou para a formação do psicólogo. Dentre eles, cinco participantes afirmaram que o PIBID contribui na formação do psicólogo, se o Programa proporciona um entendimento da subjetividade a partir da visão crítica e profunda da realidade escolar. Para esses bolsistas a contribuição está relacionada ao "[...] fato de ajudar a compreender o indivíduo em formação de outra perspectiva (escolar)" (participante 08); além disso, o entendimento das conquistas e dificuldades da realidade escolar possibilita "[...] refletir melhor a subjetividade de cada sujeito” (participante 03). Para quatro participantes, a experiência no Programa possibilita reconhecer a importância do psicólogo dentro do ambiente escolar, para eles a experiência no PIBID “[...] nos ajuda a entender como psicólogos alguns problemas de desenvolvimento ou de patologias nesse âmbito escolar" (participante 07), além de que "[...] proporcionou ver a importância que o psicólogo tem na escola" e ainda "vem contribuir com minha formação e me mostrar os diferentes papéis que o psicólogo pode contribuir na sociedade" (participante 01). Por fim, para dois participantes, o PIBID contribui para a formação do psicólogo proporcionando compreensão e reflexão acerca da complexidade da profissão.

As representações dos pibidianos da Psicologia sobre os significados da docência também foram abordadas pelo questionário aplicado. Para nove bolsistas, ser professor envolve a preocupação com a formação completa dos alunos, esta preocupação abrange, segundo estes participantes, “[...] proporcionar aos alunos uma visão crítica enquanto sujeitos [...] dar espaço de fala aos alunos" (participante 12), “[...] ajudar a formar e concretizar sonhos" (participante 07), e ainda, “[...] se preocupar com o que o aluno está realmente aprendendo, não é só passar conteúdos" (participante 01). Seis acadêmicos afirmaram fazer parte da docência o ensino, mas também a aprendizagem com os alunos, segundo um destes participantes, ser professor, além de outras significações, "é aprender todo dia." (11).

Três acadêmicos afirmaram que ser professor é ser inspiração e exemplo para os alunos; três apontaram que a prática docente é muito complexa e difícil, e ainda, foram apontadas outros significados, por um participante cada, do que é a docência, como sendo um meio de compreender o aluno como um todo; como sendo uma forma de amar e acolher o próximo; uma forma de construir um mundo melhor, e ainda, houve um participante que apontou que ser professor é passar os conteúdos curriculares para os alunos. 


\section{Discussão dos resultados}

Esta pesquisa teve como objetivo principal conhecer o impacto do Programa Institucional de Bolsa de Iniciação à Docência - PIBID sobre a formação inicial dos licenciandos em Psicologia, bem como identificar em que medida as experiências com o PIBID influenciam no interesse pelo futuro exercício da docência. É possível afirmar que as experiências vivenciadas pelos acadêmicos no Programa são consideradas positivas pelos mesmos; apesar de encararem a licenciatura como atividade desafiadora. Os licenciando consideram que a docência é uma prática gratificante e possibilita reflexões e discussões que contribuam para a qualidade da formação acadêmica e da prática enquanto bolsistas.

Conforme Assunção (1999), a licenciatura, embora seja uma habilitação possível nos cursos de graduação em psicologia, recebe um tratamento de menor importância. Isso se reflete na forma como os alunos encaram a docência. Contudo, a participação dos licenciandos em programas de formação, bem como as vivências na docência são capazes de estimular os alunos a considerarem a docência como exercício possível, após o termino do curso.

Com relação ao impacto do Programa sobre a formação acadêmica, foi possível concluir que o PIBID possibilita aos acadêmicos a outra perspectiva sobre a prática docente, uma visão crítica acerca da realidade escolar; a possibilidade de relacionar a teoria e prática e ainda, o entendimento da comunidade escolar, considerando a subjetividade de seus membros.

Diversos autores da área da educação (TARDIF, 2000; Pimenta, 2002; Perrenoud, 2002), que se ocupam com a questão da formação de professores, sinalizam para necessidade de uma formação inicial docente atrelada à prática nas escolas. O PIBID, enquanto proposta de formação docente atua nessa direção. Diferentemente da forma como alguns estágios supervisionados se organizam, nos quais o aluno é um mero observador da prática. No PIBID o aluno tem a possibilidade de assumir, na prática, a docência, fazendo isso ele se torna capaz de questionar os saberes universitários e disciplinares, com os quais tem contato no curso de formação inicial, e construir saberes a partir da prática vivenciada (Perrenoud, 2002). Sem dúvidas, essas experiências permitem a esses estudantes ter outra visão crítica da prática docente e da realidade escolar, visão e aprendizagem que talvez não fossem garantidas por meio das convencionais formas como os estágios de docência se desenvolvem.

Foi possível observar também as principais razões pelas quais os alunos de Psicologia optam por participar do PIBID, e quantos querem, de fato, atuar na docência. O fator que mais influenciou os acadêmicos a participarem do Programa foi a oportunidade de obter uma formação mais ampla, o que mostra o interesse nos acadêmicos de Psicologia em 
vivenciar diversas experiências dentro da Universidade que contribuam para o seu desenvolvimento acadêmico. A garantia destas experiências reflete-se no desejo que alguns acadêmicos apresentam de seguirem a carreira docente depois de formados. Esta constatação evidencia o potencial e abrangência do PIBID enquanto proposta que visa "incentivar a formação de professores para a educação básica". Isso nos autoriza a inferir que as vivências do PIBID abrem os horizontes de possibilidades de atuação, bem como, gera nos alunos o desejo pela profissão.

Foi percebido, também, que outros fatores influenciam o interesse pelo Programa, entre eles a identificação com a docência, as horas complementares obtidas através da participação no Programa, e ainda, a bolsa oferecida pelo PIBID, este fator se mostrou o menos influente na escolha dos acadêmicos pelo Programa, o que demonstra o maior interesse dos acadêmicos na formação acadêmica em detrimento ao recurso financeiro oferecido.

Outra questão percebida através da pesquisa foi com relação às narrativas dos acadêmicos acerca das suas experiências no PIBID. A partir da diversidade de acadêmicos matriculados em diversos semestres foi possível comparar a qualidade dos discursos sobre esta temática. De modo geral, não houve grande discrepância entre os discursos dos acadêmicos dos primeiros semestres e dos últimos semestres; todos os acadêmicos consideram ser a experiência positiva, possibilitando enriquecimento na formação acadêmica e discussões que proporcionam crescimento dos acadêmicos, enquanto docentes, e consequentemente, das instituições de ensino básico e superior.

\section{Conclusão}

O Programa Institucional de Bolsa de Iniciação à Docência (PIBID) se constitui, enquanto política pública, como uma abertura para que os acadêmicos atuem na licenciatura. Apesar de o campo de atuação do licenciado em Psicologia ser escasso e ainda muito restrito, esta formação tem contribuído em diversas esferas de conhecimento dos acadêmicos, possibilitando, ainda, maior compreensão e visão crítica acerca do sistema educacional e do processo de ensino e aprendizagem.

A partir da pesquisa realizada, percebeu-se que, de modo geral, o impacto do PIBID na formação dos bolsistas do curso de Psicologia se apresentam como positivo, oferecendo oportunidades de atuação no sistema educacional, experiências profissionais relevantes, e ainda, oportunizando reflexão crítica sobre as relações estabelecidas no processo de ensino e aprendizagem, além de se caracterizar como incentivo à atuação na docência. 
Assim, entendemos que o PIBID consegue suprir as expectativas iniciais dos pibidianos de obter formação ampla e diversificada, uma vez que, além do conhecimento teórico, ele possibilita também a prática, tornando a formação inicial de professores rica em experiências para a vida profissional e pessoal dos pibidianos.

Durante a produção deste trabalho, percebeu-se a escassez de material e estudos que verificassem a influência da licenciatura na formação de psicólogo dos acadêmicos, portanto consideramos importante a produção de mais pesquisas e estudos que contribuam para o conhecimento deste tema, pois o mesmo se apresenta como relevante para a comunidade acadêmica e social. Neste sentido, com este trabalho não se pretende esgotar as discussões acerca da licenciatura em Psicologia e a influência do PIBID no processo de formação, mas sim, incentivar discussões e pesquisa acerca deste tema entre a comunidade acadêmica, a educação básica e a sociedade.

\section{Referências}

ANDRÉ, M. E. D. A. \& LÜDKE, M. Pesquisa em Educação: abordagens qualitativas. São Paulo: EPU, 1986.

ASSUNÇÃO, M. M. S. Curso de Psicologia: algumas reflexões sobre o bacharelado e a licenciatura. Educação em Revista, Belo Horizonte, nº 29, 1999.

BRASIL. Ministério da Educação. Conselho Nacional de Educação - Câmara de Educação Superior. Resolução $\mathrm{N}^{\circ}$ 5, de 15 de março de 2011. Disponível em <portal.mec.gov.br/index.php> acesso em março/2017.

BRASIL, Ministério da Educação. Portaria nº 096, de 18 de julho de 2013.

CIRINO, S. D.; KNUPP, D. F. D.; LEMOS, L. S. \& DOMINGUES, S. As novas diretrizes curriculares: uma reflexão sobre a licenciatura em Psicologia. Temas psicol. [online]. 2007, vol.15, n.1, pp. 23-32. Disponível em: <http://pepsic.bvsalud.org/scieloOrg/php/reference.php?pid.> acesso em março de 2017.

LIBÂNEO, J. C. Democratização da Escola Pública: a pedagogia crítico-social dos conteúdos. 9. ed. São Paulo: Edições Loyola, 1990.

Organização e Gestão da Escola: teoria e prática. 5. ed. ver. e ampl. Goiânia: Editora Alternativa, 2004. 
LUCKESI, C. C. Filosofia da Educação. São Paulo: Cortez, 1994.

PERRENOUD, P. A Prática reflexiva no Ofício do professor: profissionalização e razão pedagógica. Porto Alegre: Artemed editora, 2002.

PIMENTA, S. G. Professor Reflexivo no Brasil: gênese e crítica de um conceito. São Paulo: Cortez, 2002.

TARDIF, M. Saberes Profissionais dos Professores e Conhecimentos Universitários: elementos para uma epistemologia da prática profissional dos professores e suas consequências em relação à formação para o magistério. Revista Brasileira de Educação. $\mathrm{n}^{\circ}$ 13, 2000.

ZABALA, A. A função social do ensino e a concepção sobre os processos de aprendizagem: instrumentos de análise. In: A Prática Educativa: como ensinar. Trad. Ernani F. da F. Rosa. Porto Alegre: Artmed, 1998. p. 27-52. 